\title{
Comparison of molecular and microscopic technique for detection of Theileria annulata from the field cases of cattle
}

\author{
H. C. Chauhan ${ }^{1}$, B. K. Patel ${ }^{1}$, A. G. Bhagat ${ }^{2}$, M. V. Patel ${ }^{2}$, S. I. Patel ${ }^{2}$, S. H. Raval ${ }^{3}$, H. H. Panchasara ${ }^{4}$, M. D. Shrimali ${ }^{1}$,
} A. C. Patel ${ }^{2}$ and B. S. Chandel ${ }^{1}$

1. Division of Animal Biotechnology, College of Veterinary Science \& Animal Husbandry, Sardarkrushinagar Dantiwada Agricultural University, Sardarkrushinagar - 385 506, Gujarat, India; 2. Division of Veterinary Microbiology,

College of Veterinary Science \& Animal Husbandry, Sardarkrushinagar Dantiwada Agricultural University,

Sardarkrushinagar - 385 506, Gujarat, India; 3. Division of Veterinary Pathology, College of Veterinary Science \& Animal House, Sardarkrushinagar Dantiwada Agricultural University, Sardarkrushinagar - 385 506, Gujarat, India; 4.

Teaching Veterinary Clinical Complex (College Clinics), College of Veterinary Science \& Animal House, Sardarkrushinagar Dantiwada Agricultural University, Sardarkrushinagar - 385 506, Gujarat, India.

Corresponding author: A. C. Patel, e-mail: viroarun@gmail.com, HCC: hcchauhan1972@gmail.com, BKP: bharatpatel1063@yahoo.com, AGB: abidalibhagat@gmail.com, MVP: patelmv960@gmail.com, SIP: dr.sanjivpatel8790@gmail.com, SHR: samirraval81@gmail.com, HHP: harshadlrs@yahoo.co.in, MDS: shrimali.vets@gmail.com, BSC: bschandel13@gmail.com

Received: 23-06-2015, Revised: 08-10-2015, Accepted: 19-10-2015, Published online: 28-11-2015

doi: 10.14202/vetworld.2015.1370-1374 How to cite this article: Chauhan HC, Patel BK, Bhagat AG, Patel MV, Patel SI, Raval SH, Panchasara HH, Shrimali MD, Patel AC, Chandel BS (2015) Comparison of molecular and microscopic technique for detection of Theileria annulata from the field cases of cattle, Veterinary World 8(11): 1370-1374.

\begin{abstract}
Aim: Tropical theileriosis is fatal hemoprotozoal disease of dairy animals caused by Theileria annulata. The aim of the present study was to detect the T. annulata and comparison of results of molecular and microscopic techniques.

Materials and Methods: A total of 52 blood samples were collected from the cattle suspected for theileriosis across the Banaskantha district. All the samples were screened for theileriosis using Giemsa's staining technique and polymerase chain reaction (PCR).

Results: Total of 17 (32.69\%) and 24 (46.15\%) samples were found positive for theileriosis by microscopic examination and PCR test, respectively. It revealed that the study area is endemic for theileriosis, and the microscopic technique has $70.83 \%$ sensitivity and $100 \%$ specificity with respect to PCR technique.

Conclusion: It may be concluded from the present study that the PCR is comparatively sensitive technique than microscopic examination and may be recommended to use in the field for screening of theileriosis in the study area, where a high prevalence of diseases have been reported due to intensive dairy farming.
\end{abstract}

Keywords: Giemsa staining, polymerase chain reaction, theileriosis.

\section{Introduction}

Theileriosis is a hemoprotozoan parasitic disease caused by Theileria annulata affects mainly crossbred cattle. The disease is transmitted mainly by ticks of the genus Hyalomma and characterized by lymphadenopathy, splenomegaly, fever, anemia, weakness, and loss of body weight $[1,2]$. It is an economically important tick-borne disease in tropical and sub-tropical regions including India [3]. In India, Gujarat is one of the leading states in milk production contributing about 10.32 million tons per year, having around 17 lakh exotic/crossbred milch cattle [4,5]. Rearing of crossbred cattle has been increased in Gujarat since last decade, which has resulted in to increased milk production of the state; however, it has also increased the incidence of various hemoprotozaoan infections. Theileriosis has become endemic in the state and prevalent as clinically inapparent/ carrier, and may cause fatal disease [6], resulting in

Copyright: The authors. This article is an open access article licensed under the terms of the Creative Commons Attributin License (http:// creative commons.org/licenses/by/2.0) which permits unrestricted use, distribution and reproduction in any medium, provided the work is properly cited. to substantial economic loss to the state. Therefore, early and specific diagnosis of disease is of paramount importance to reduce the economic loss as well as to maintain the good health status of the high milk producing animals.

The diagnosis of theileriosis is mainly based on clinical signs and confirmed by microscopic examination of Giemsa stained thin blood or lymph node smears for presence of piroplasms in red blood cells and macroschizonts in lymphocytes. Diagnosis based on the clinical signs is not trustful in many cases, as other parasitic diseases also show clinical signs similar to those of tropical theileriosis. Whereas, microscopic method of diagnosis demands expertise in slide reading for sub-clinical or chronic infections cases, as parasitemias in such cases are often extremely low and piroplasm may be difficult to find in stained blood smears. This conventional method is difficult to perform and time consuming to identify piroplasmic form within the erythrocytes from carrier animals [7]. Which ultimately increase the chances of getting false negative or false positive results [8]. Indirect immunofluorescent antibody test (IFAT) is OIE recommended test for diagnosis of parasitic diseases. It 
detects circulating antibodies against antigens of piroplasms and/or macroschizonts but the cross-reactivity with antibodies directed against other Theileria species limits the specificity of IFAT. Thus, false positive or negative results are frequently observed [7,9-11]. Moreover, antibodies tend to disappear in long-term carriers although Theileria piroplasms persist. Hence, animals with negative serological test may be positive for T. annulata piroplasms and can be act as a source of infection for susceptible animals. Furthermore, it is not applicable for the determination of pre-symptomatic or carrier animals, where parasitemia is very low [12]. Therefore, diagnostic method having high sensitivity and specificity than routinely using serological and microscopic examination is the need of the hour.

In the present study, molecular method (polymerase chain reaction [PCR]) has been developed to diagnose the theileriosis from the persistently infected cattle [13] and the prevalence of T. annulata was recorded using microscopic method and PCR.

\section{Materials and Methods}

\section{Ethical approval}

All samples were collected as per standard sample collection method without any stress/harm to animals.

\section{Collection of samples}

Banaskantha district was selected as study area for present study. It lies on north-west side of Gujarat State, India between 23.33 to 24.45 north latitude and 72.15 to 73.87 east longitudes. Total 52 blood samples were collected in EDTA containing tubes from cattle of above 1 year age. The samples were collected from the animals which were showing symptoms like high fever, swelling of sub-mandibular and sub-scapular lymph nodes and hemoglobinuria or which have the problem of tick infestation. Thin blood smears were prepared from each sample at the site of sample collection, and remaining part of sample was brought to the laboratory over ice for further investigation.

\section{Microscopic examination}

A thin blood smear from each sample was prepared and fixed in methanol for $5 \mathrm{~min}$ and stained with Giemsa stain for $30 \mathrm{~min}$. Blood smears were examined for intraerythrocytic forms of Theileria spp. piroplasma under $\times 100$ objective magnification. More than 20 microscopic fields per slide were observed before considering it as negative; whereas, even the presence of single piroplasms was recorded as positive for Theileria.

\section{DNA extraction}

DNA was extracted from the blood samples using Qiamp DNA blood and tissue kit (Qiagen, Netherland) following the manufacture's protocol. In brief, $20 \mu \mathrm{lof}$ proteinase $\mathrm{K}$ was added into $2 \mathrm{ml}$ of microcentrifuge tube containing $100 \mu 1$ of anticoagulant treated blood.
$200 \mu 1$ of AL buffer was added into microcentrifuge tube. Mixture was thoroughly mixed by vortexing and incubated at $56^{\circ} \mathrm{C}$ for $10 \mathrm{~min}$. Then $200 \mu \mathrm{l}$ of ethanol was added and further mixture was thoroughly mixed by vortexing. Mixture was taken in DNeasy Mini spin column placed in a $2 \mathrm{ml}$ collection tube. Mixture was centrifuge at $8000 \mathrm{rpm}$ for $1 \mathrm{~min}$ and flow-through and collection tube were discarded. Spin column was placed in a new $2 \mathrm{ml}$ collection tube. $500 \mu \mathrm{l}$ of AW1 buffer was added and then again mixture was centrifuge at $8000 \mathrm{rpm}$ for $1 \mathrm{~min}$ and flow-through and collection tube were discarded. Spin column was placed in a new $2 \mathrm{ml}$ collection tube. $500 \mu \mathrm{l}$ of AW2 buffer was added then mixture was centrifuge at $14,000 \mathrm{rpm}$ for $3 \mathrm{~min}$ and flow-through and collection tube were discarded. Spin column was transferred to a new $2 \mathrm{ml}$ microcentrifuge tube. DNA was eluted by adding $200 \mu 1$ of AE buffer at the center of the spin column membrane. Mixture was incubated at room temperature $\left(15-25^{\circ} \mathrm{C}\right)$ for $1 \mathrm{~min}$ and then mixture was centrifuged at $8000 \mathrm{rpm}$ for $1 \mathrm{~min}$.

\section{PCR}

For detection of T. annulata, forward primer 5'- CCAGGACCACCCTCAAGTTC-3' and reverse primer 5'- GCATCTAGTTCCTTGGCGGA-3' were used, which amplify $430 \mathrm{bp}$ fragment of the Tams 1 gene which encodes $30-\mathrm{kDa}$ merozoitepiroplasm surface antigen of T. annulata [14]. PCR was carried out in $200 \mu 1$ PCR tubes using Nexus gradient Master cycler (Eppendorf, Germany). Each $15 \mu$ of the PCR mixture comprised of $1 \mu \mathrm{l}$ of DNA, $7.5 \mu 1$ of $\times 2$ PCR master mix, $0.5 \mu$ l of each Tams 1 forward and reverse primer and $5.5 \mu 1$ nuclease free water. The PCR conditions includes initial denaturation at $95^{\circ} \mathrm{C}$ for $5 \mathrm{~min}$; followed by 30 cycles of $95^{\circ} \mathrm{C}$ for $30 \mathrm{~s}$ (denaturation), $55^{\circ} \mathrm{C}$ for $30 \mathrm{~s}$ (annealing) and $72^{\circ} \mathrm{C}$ for $30 \mathrm{~s}$ (extension); with a final extension step of $72^{\circ} \mathrm{C}$ for 4 min. $5 \mu 1$ of amplified PCR product was mixed with $1 \mu 1$ of $\times 6$ gel loading dye and subjected to electrophoresis in $1.5 \%$ agarose gel along with 100 bp DNA ladder. The images were captured and documented using gel documentation system (Bio Rad., USA).

\section{Determination of sensitivity and specificity of micro- scopic examination}

The sensitivity and specificity of microscopic method was determined in respect to PCR assay using following formula use by Noaman [15].

$$
\text { Sensitivity }(\%)=\frac{\left(\begin{array}{l}
\text { PCR and Giemsa's } \\
\text { staining positive }
\end{array}\right)}{\text { PCR positive }} \times 100
$$

$$
\text { Sensitivity }(\%)=\frac{\left(\begin{array}{l}
\text { PCR and Giemsa's } \\
\text { staining negative }
\end{array}\right)}{\text { PCR negative }} \times 100
$$




\section{Results}

\section{Microscopic examination of blood smears}

Out of 52 samples, 17 (32.69\%) samples were found positive in Giemsa's stained blood smear (Table-1). All the samples had showed comma and signet-ring (diameter of 0.5-1.5 $\mu \mathrm{m}$ ) shaped intra-cytoplasmic bodied which was seems to be Theileria piroplasms (Figure-1). Sensitivity and specificity of microscopic examination was found to be $70.83 \%$ and $100 \%$, respectively in respect to $100 \%$ PCR assay (Table-2).

\section{PCR}

On agarose gel electrophoresis of PCR products, $24(46.15 \%)$ samples showed specific amplification for T. annulata corresponding to $430 \mathrm{bp}$ (Figure-2).

\section{Treatment}

All the theileriosis positive cattle detected by PCR were treated with single dose of buparvaquone (2.5 $\mathrm{mg} / \mathrm{kg}$ body weight) and hematinic (feritas at $10 \mathrm{ml} \mathrm{I} / \mathrm{M})$. Out of 24 theileriosis positive cattle, $21(87.5 \%)$ cattle was respond to the treatment and recovered in 4-5 days.

\section{Discussions}

T. annulata is a causative agent of tropical theileriosis, is an omnipresent parasite in India and has been reported from every part of the country. The disease is important in India and it was estimated that 250 million cattle in countries including Iran, Turkey, India and China are at a risk of the disease. It causes serious economic loss to the economy of various developing countries in terms of loss of livestock and production $[16,17]$. In recent time, production of milk has been increased in Banaskantha district, Gujarat. Eventually, rearing of Holstein Friesian, Jersy and their crossbred animals have been increased. Therefore, prevalence of hemoprotozoal diseases like theileriosis and babesiosis is

Table-1: Comparison of results of microscopic examination and PCR assay for detection of $T$. annulata from the field samples.

\begin{tabular}{lcc}
\hline Method/technique & \multicolumn{2}{c}{$\begin{array}{l}\text { Results of microscopic } \\
\text { examination technique }\end{array}$} \\
\cline { 2 - 3 } & Positive & Negative \\
\hline Results of PCR assay & 17 & 07 \\
Positive & 00 & 28 \\
Negative & & \\
\hline
\end{tabular}

$\mathrm{PCR}=$ Polymerase chain reaction, $T$. annulata $=$ Theileria annulata increased, which causes high mortality and leads to huge economic losses.

The present study envisaged the appraisal of diagnosing theileriosis in dairy crossbred cattle using microscopic slide examination as well as PCR. The sensitivity and specificity of each technique were also compared simultaneously. On examination of 52 samples, it was revealed that microscopic examination has $70.83 \%$ and $100 \%$ sensitivity and specificity, respectively, which corroborates the observation made by Noaman [15]. In the present study, less sensitivity of microscopic method observed which might be due to artifacts, low parasitemia, and destruction of piroplasmic forms in red blood cells because of hemolysis, thickness and dirtiness of slides. Less sensitivity of microscopic examination has also been reported by other workers $[18,19]$. The present

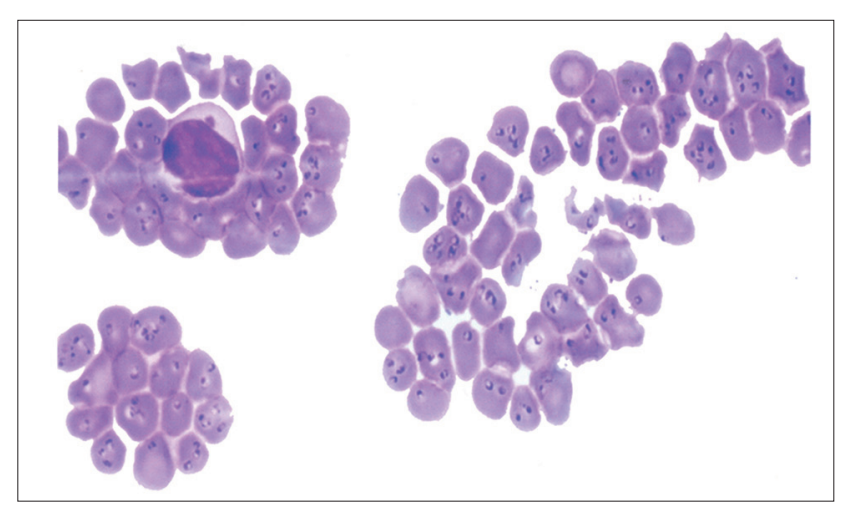

Figure-1: Blood smear stained with field stain showing the comma and signet-ring shaped intra-cytoplasmic bodied of Theileria organism (1000X magnification).

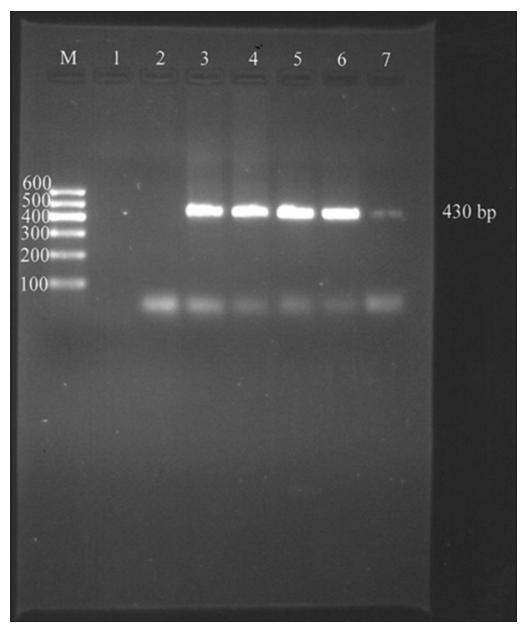

Figure-2: Agarose gel electrophoresis showing the $430 \mathrm{bp}$ PCR product. M: 100 bp molecular wt. DNA marker, Lane 1: Negative control, Lane 2: Negative sample, Lane 3 - 7: Positive samples showing specific amplicon of $430 \mathrm{bp}$ size.

Table-2: Sensitivity and specificity of microscopic method in respect to PCR assay for detection of $T$. annulata from the field samples.

\begin{tabular}{lcccc}
\hline $\begin{array}{l}\text { Method/ } \\
\text { technique }\end{array}$ & $\begin{array}{c}\text { Number of samples } \\
\text { examined }\end{array}$ & $\begin{array}{c}\text { Number of positive } \\
\text { samples }\end{array}$ & $\begin{array}{c}\text { Sensitivity } \\
(\%)\end{array}$ & $\begin{array}{c}\text { Specificity } \\
(\%)\end{array}$ \\
\hline Microscopy & 52 & 17 & 70.83 & 100 \\
PCR & 52 & 24 & 100 & 100 \\
\hline
\end{tabular}

$\mathrm{PCR}=$ Polymerase chain reaction, $T$. annulata $=$ Theileria annulata 
study showed $32.69 \%(17 / 52)$ and $46.15 \%$ (24/52) prevalence of disease based on microscopic examination and PCR, respectively. The high prevalence of theileriosis observed in the present study may be attributed due to high abundance of tick vector, because the hot and humid environment is very conducive for ticks and ultimately for the survival of the piroplasm. Previous workers has also reported the high sensitivity of PCR, which supports our findings that the modern techniques like PCR is comparatively more sensitive and specific than routine microscopic examination [7,15-17,20].

Microscopic examination of Giemsa stained blood smear is routinely used for diagnosis of theileriosis worldwide including India, because it is simple to perform, quick and cost effective techniques. However, less sensitivity makes it difficult to detect carrier cases [21]. Similarly, serological test has also limited value because antibodies specific to theileriosis disappear rapidly, and may give false negative results in case of carrier animals. Detection of carrier animal has special value in control program for theileriosis, as these animals pose a risk for maintenance and perpetuation of Theileria in environment through animal-tick-animal cycle. Therefore, in such circumstances PCR-based detection is a better choice for quick and precise diagnosis of the disease. PCR-based detection of theileriosis is used worldwide and has high sensitivity and specificity [13,21]. Roy et al., [22] reported that PCRbased assay detects $0.00008 \%$ erythrocytic parasitemia equivalent to 16 piroplasm of T. annulata. Therefore, it may have special value in diagnosis of diseases from Banaskantha district or elsewhere in the state/country, which have more number of crossbred cattle and high milk production. Using this technique results can be obtained within 3-4 h after receiving the samples and may help to decide the line of treatment, which will results in rapid decision making to control the disease with cost effective treatment in the shortest duration. As described earlier, this is mainly a disease of high yielding exotic crossbred animals, and if not treated rapidly with effective treatment animal becomes anemic, loss weight, decreased milk yield and in extreme cases may lead to death. This will add ups to the economic burdens to the farmers. Moreover, if confirmatory diagnosis is not made than animals will be treated for some other disease conditions, which will ultimately result in unnecessary inoculation of antibiotics and other drugs to the animals. This will also increase the unwanted economic burden on the animal owner as well there will be problem of unwanted antibiotic/drug residue in milk and milk products and development of antibiotic resistant, which will eventually result in rejection of milk and milk product in the international market, pose human health risk. Therefore, farmers may afford this test for routine screening of herd animals.

\section{Conclusions}

It may be concluded from the present study that the molecular technique (PCR) is more sensitive than microscopic examination for diagnosis of theileriosis. Therefore, it may use for screening of samples suspected for theileriosis and has special value in endemic area like Gujarat, where intensive farming has been increased.

\section{Authors' Contributions}

HCC designed the work. MVP, BKP, SHR, HHP, SIP, MDS and AGB conducted experiments including molecular technique and microscopic examination. ACP had helped in preparation and submission of manuscript. BSC all supervision of the work and examining manuscript. All authors read and approved the final manuscript.

\section{Acknowledgments}

The authors wish to thank the Dean, Veterinary College, SDAU, Sardarkrushinagar for providing necessary facilities and laboratory for research and financial help.

\section{Competing Interests}

The authors declare that they have no competing interests.

\section{References}

1. Omer, O.H., El-Malik, K.H., Mahmoud, O.M., Haroun, E.M., Hawas, A., Sweeney, D. and Magzoub, M. (2002) Hematological profiles in pure bred cattle naturally infected with Theileria annulata in Saudi Arabia. Vet. Parasitol., 107(1-2): 161-168.

2. El-Deeb, W.M. and Younis, E.E. (2009) Clinical and biochemical studies on Theileria annulata in Egyptian buffaloes (Bubalus bubalis) with particular orientation to oxidative stress and ketosis relationship. Vet. Parasitol., 164(2-4): 301-305.

3. Uilenberg, G. (1981) Theileria species of domestic livestock. In: Irvin, A.D., Cunningham, M.P. and Young, A.S., editors. Advances in the Control of Theileriosis. Martinus Nijhoff, The Hague. p4-37.

4. Available from: http://www.nddb.org/AnnualReports/ nddb-annual-report-2011-2012.pdf. Accessed on 30-04-2015.

5. Availablefrom:http://www.dahd.nic.in/dahd/WriteReadData/ Livestock.2012.pdf. Accessed on 24-04-2015.

6. Taylor, M.A., Coop, R.L. and Wall, R.L. (2007) Veterinary Parasitology. $3^{\text {rd }}$ ed. Blackwell Publishing, Oxford.

7. Nourollahi-Fard, S.R., Khalili, M. and Ghalekhani, N. (2012) Detection of Theileria annulata in blood samples of native cattle by PCR and smear method in Southeast of Iran. J. Parasitol. Dis., 39(2): 249-252.

8. Aktas, M., Altay, K. and Dumanli, N. (2006) A molecular survey of bovine Theileria parasites among apparently healthy cattle and with a note on the distribution of ticks in eastern Turkey. Vet. Parasitol., 138(3-4): 179-185.

9. OIE. (2014) Manual of Diagnostic Tests and Vaccines for Terrestrial Animals. $7^{\text {th }}$ ed., Vol. 1-2. Office International Des Epizooties, Paris.

10. Pipano, E. and Cahana, M. (1969) Fluorescent antibody test for the serodiagnosis of Theileria annulata. J. Parasitol., 55(4): 765 .

11. Burridge, M.J., Brown, C.G.D. and Kimber, C.D. (1974) Theileria annulata: Cross reactions between a cell culture schizont antigen and antigens of East African Theileria species in the indirect fluorescent antibody test. Exp. Parasitol., 35: 374-380.

12. Friedhoff, K. and Bose, R. (1994) Recent developments in diagnostics of some tick-borne diseases. In: 
Uilenberg, G., Permin, A. and Hansen, J.W., editors. Use of Applicable Biotechnological Methods for Diagnosing Haemoparasites. Proceedings of the Expert Consultation, Merida, Mexico, 4-6 October 1993. Food and Agriculture Organisation of the United Nations (FAO), Rome, Italy. p46-57.

13. Altay, K., Aydin, M.F., Dumanli, N. and Aktas, M. (2008) Molecular detection of Theileria and Babesia infections in cattle. Vet. Parasitol., 158(4): 295-301.

14. Kundave, V.R., Patel, A.K., Patel, P.V., Hasnani, J.J. and Joshi, C.G. (2014) Qualitative and quantitative assessment of Theileria annulata in cattle and buffaloes polymerase chain reaction. Trop. Biomed., 31(4): 728-735.

15. Noaman, V. (2014) Comparison of molecular and microscopic technique for detection of Theileria spp. in carrier cattle. J. Parasit. Dis., 38(1): 64-67. Doi: 10.1007/ s12639-012-0196-y.

16. Dumanli, N., Aktas, M., Cetinkaya, B., Cakmak, A., Koroglu, E., Saki, C.E., Erdogmus, Z., Nalbantoglu, S., Ongor, H., Simsek, S., Karahan, M. and Altay, K. (2005) Prevalence and distribution of tropical theileriosis in eastern Turkey. Vet. Parasitol., 127(1): 9-15.

17. Azizi, H., Shiran, B., Farzaneh, D.A., Salehi, F. and
Taghadosi, C. (2008) Detection of Theileria annulata by PCR and its comparison with smear method in native carrier cows. Biotechnology, 79(3): 574-577.

18. Nayel, M., El-Dakhly, K,M., Aboulaila, M., Elsify, A., Hassan, H., Ibrahim, E., Salama, A. and Yanai, T. (2012) The use of different diagnostic tools for Babesia and Theileria parasites in cattle in Menoufia, Egypt. Parasitol. Res., 111(3):1019-1024. Doi: 10.1007/s00436-012-2926-6.

19. Hoghooghi-Rad, N., Ghaemi, P. and Shayan, P. (2011) Detection of native carrier cattle infected with Theileria annulata by seminested PCR and smear method in Golestan province of Iran. World Appl. Sci. J., 12(3): 317-323.

20. Kohli, S., Atheya, U.K. and Thapliyal, A. (2014) Prevalence of theileriosis in cross-bred cattle: Its detection through blood smear examination and polymerase chain reaction in Dehradun district, Uttarakhand, India. Vet. World, 7(3): 168-171.

21. Shayan, P. and Rahbari, S. (2005) Simultaneous differentiation between Theileria sp. and Babesia sp. on stained blood smear using PCR. Parasitol. Res., 97(4): 281-286.

22. Roy, K.C., Ray, D., Bansal, G.C. and Singh, R.K. (2000) Detection of Theileria annulata carrier cattle by PCR. Indian J. Exp. Biol., 38: 283-284. 